\title{
RESEARCH ON NON-DESTRUCTIVE TESTING TECHNOLOGY IN RENOVATING PROJECTS OF MUKDEN PALACE
}

\author{
C. $\mathrm{Li}^{1}$, J. Yang ${ }^{1}$, X. Zhang ${ }^{1}$, M. Fu ${ }^{2}$ \\ ${ }^{1}$ Architecture School, Tianjin University, China - li_chengyuan@tju.edu.cn, yangjing827@aliyun.com,601104951@qq.com \\ ${ }^{2}$ Xiongan New Area management committee 1028678992@qq.com
}

KEY WORDS: Non-destructive Testing (NDT), Mukden Palace, Ground Penetrating Radar, Stress Wave, Resistograph

\begin{abstract}
:
With the increasing emphasis on the conservation of cultural relics, the renovation work of historic buildings has become more and more important. Basically, most of the ancient buildings in China are wooden structure. Wood is a flexible material which could resist deformation in the earthquake. The drawback, however, is that they are susceptible to temperature, humidity and other external influences (which will lead to rot, cracks, tilt, foundation settlement, etc.), and poses a hidden danger to entire architecture. Besides, after years of use, the decline in mechanical properties could affects their bearing capacity. Moreover, traditional renovation methods, determining renovation and demolition in the absence of accurate and effective detection and evaluation methods, like eyeballing, knocking, which are simple and depend largely on manual experience and lacks of accuracy, will cause the loss of historical information of ancient construction. Also, Traditional way of stylobate repairing can only be qualitative analysis which are visually or empirically, deciding partial repair or comprehensive replacement. Internal damage remains unclearly and inaccurately that often result in the loss of historical information and over-repair of heritage. Paper aims to interpret with two typical example in Mukden Palace, where located in the temperate sub-humid continental climate, with a huge temperature difference between day and night, one is the stone stylobate of Dazheng Hall, the palace used for holding ceremonies, the other is the wooden structure of Ancestral Temple. Both faced with varying degrees of damage, such as foundation broken, frieze panel inclined and pillar cracked. Non-destructive Testing (NDT) Technology using in those two projects includes 3D scanning, ground penetrating, concrete ultrasonic testing and mineral element analyzing that can collect data more comprehensive than just using traditional methods, especially for internal damage. Then generating the quantitative analysis of damage category. Furthermore, discussing cause of damage and moderately protection methods of the stone stylobate and the wooden structure on the basis of testing. As well as providing references of repairing project of traditional Chinese stony heritage.
\end{abstract}

Non-destructive Testing (NDT) Technology using in thoes projects includes 3D scanning, ground penetrating, concrete ultrasonic testing and mineral element analyzing that can collect data more comprehensive than just using traditional methods, especially for internal damage. Then generating the quantitative analysis of damage category. Today, digital technology, especially non-destructive testing technology, could provide accurate records in capturing detailed physical characteristics of structures, such as geometric deformation and invisible damage, will prevent secondary man-made destruction in the repair process. The paper, in the form of two case studies of the stone stylobate of Dazheng Hall and the wooden structure of Ancestral Temple in Mukden Palace, aims to introduce nondestructive testing technology (ground penetrating radar, stress wave, resistograph and so on) and explore an appropriate protection method in renovation projects of traditional Chinese architecture.

\section{MUKDEN PALACE}

Shenyang (Mukden) is in the temperate sub-humid continental climate, with a harsh annual temperature difference, the lowest temperature can down to $-29{ }^{\circ} \mathrm{C}$ whereas the highest temperature can reach to $36^{\circ} \mathrm{C}$, and huge temperature difference between day and night. The average annual rainfall is about 850 $\mathrm{mm}$. Combined with the long winter, the effect of frost heave is obvious.
Shenyang Imperial Palace (Mukden Palace, Figure.1), located in the old city center of the Ming and Qing dynasties, shenhe district in Shenyang, was the palace of the Qing imperial family before the Manchu conquest of China and the temporary palace after. It was founded in 1625 A.D., basically finished in 1636, large-scale renovated in Qianlong period and covers an area of about 60000 square meters so far. Since 1926, its buildings have been used as the Shenyang Palace Museum step by step. In 1961 , it was designated by the state council of the People's Republic of China as the first key cultural relics site under the state protection and listed of "Imperial Palaces of the Ming and Qing Dynasties in Beijing and Shenyang" project in the world heritage list in July 2004.

Early construction of Mukden Palace began in 1625 by Nurhaci, the founder of the Qing dynasty. By 1631, additional structures were added during the reign of Nurhaci's successor, Huangtaiji. The Mukden Palace was built to resemble the Forbidden City in Beijing. However, the palace also exhibits hints of Manchu and Tibetan styles.In 1780, the Qianlong Emperor further expanded the palace. Successive Qing emperors usually stayed at Mukden Palace for some time each year. 


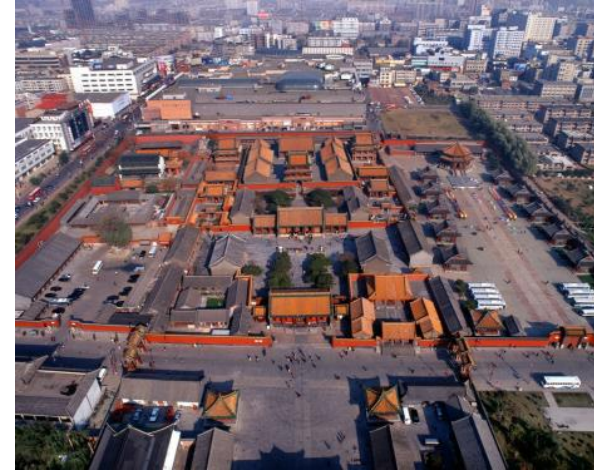

Figure 1. The aerial view of Mukden Palace

\subsection{Dazheng Hall}

The Dazheng Hall (Figure.2) is located in the east road of Shenyang Palace Museum with the Eight Banners' Pavilion. All of them were built around the 10th year of Tianming (1625). The Eight Banners' Pavilion are ten pavilions in front of the Dazheng Hall and forming an open space together. The complex is used for daily politics discussion and temporary military build-up. Its architectural form reflects the special political form of the Eight Banners system in the Later Jin dynasty that is an isolated case in the existing buildings.

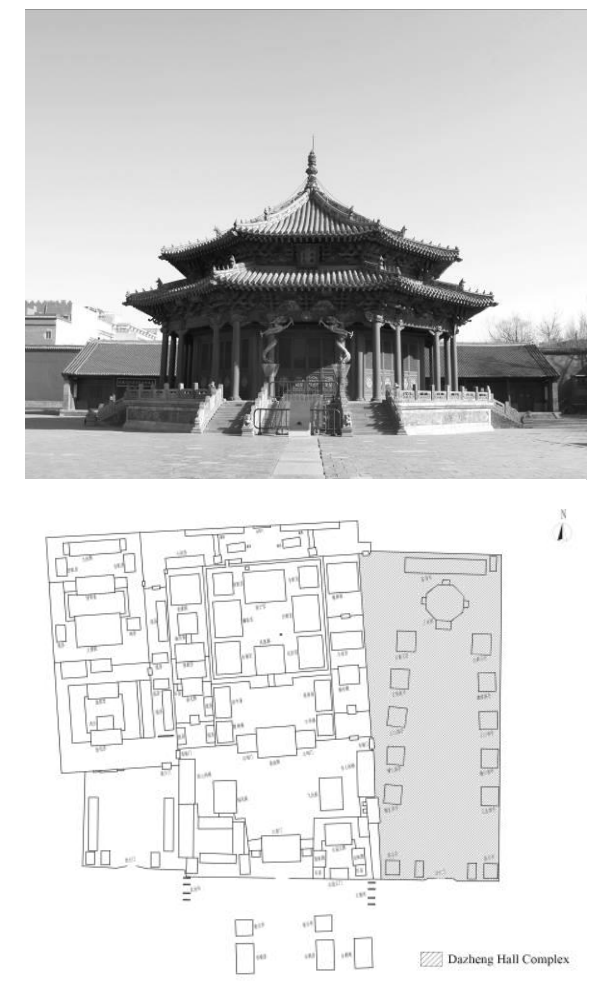

Figure. 2. Site of Dazheng Hall Complex in Mukden Palace

There are some problems such as uneven settlement of stylobate, cracking and dislocation of masonry structure, incline of stony frieze panel existing influenced by its own gravity, rain, freezing and thawing, weathering erosion, etc. Combining observing, photographing, measuring, 3D scanning, ground penetrating radar exploring, concrete ultrasonic testing and mineral element analyzing tries to diagnose damage of stylobate all-side, the paper also considers if the process could be a well non-destructive testing process enough. For same methods using, paper just takes Dazheng Hall testing as an example.

\subsection{Ancestral Temple in Mukden Palace}

Ancestral Temple, located in Mukden Palace on the east side of the Great Qing Gate, is an antique-courtyard-style building (Figure 3). The temple is off the beaten track as it doesn' $t$ belong to the main part of the palace. The Ancestral Temple was the main spot for feudal emperors to worship the ancestors. At first, instead of the present position, the temple was "about $2.5 \mathrm{~km}$ east to the FU Jin gate (the East gate) of Mukden palace ". According to "Qing Gaozong Record" Volume 1065, in the August of Qianlong forty-three years (1778), When Qianlong was on his third tour of Mukden, he "commanded to rebuilt Temple of Heaven and Temple of Earth in Mukden, and move Ancestral Temple to the east of the Qing Gate", to revive the system of this provisional capital. So we can see that the construction of Ancestral temple was started in Qianlong fortythree years (1778), and after more than two years, completed in Qianlong forty-six years (1780).

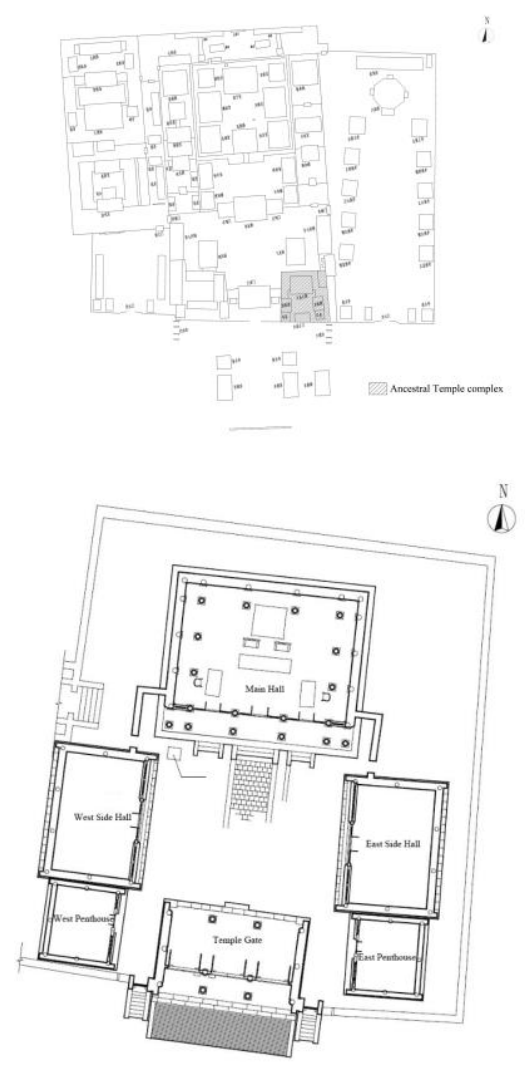

Figure. 3. Site of Ancestral Temple Complex in Mukden Palace

Ancestral Temple, located in Mukden Palace on the east side of the Great Qing Gate, is an antique-courtyard-style building (Figure 3). The temple is off the beaten track as it doesn' $t$ belong to the main part of the palace. The Ancestral Temple was the main spot for feudal emperors to worship the ancestors. At first, instead of the present position, the temple was "about $2.5 \mathrm{~km}$ east to the FU Jin gate (the East gate) of Mukden palace ". According to "Qing Gaozong Record" Volume 1065, in the August of Qianlong forty-three years (1778), When Qianlong was on his third tour of Mukden, he "commanded to rebuilt Temple of Heaven and Temple of Earth in Mukden, and move Ancestral Temple to the east of the Qing Gate", to revive the 
system of this provisional capital. So we can see that the construction of Ancestral temple was started in Qianlong fortythree years (1778), and after more than two years, completed in Qianlong forty-six years (1780).

Ancestral Temple was built on an independent two-meters high platform, and formed a typical enclosed courtyard. This building complex consists of six buildings: main hall, temple gate, two side halls with one penthouse each. The main hall is an extends five Bays, building with front porch and hip-andgable roof covered with yellow glazed tiles. To the southwest of the main hall, located the Fen Jin pavilion, which was used for sacrifice. To the East and West of the main hall, there are two side hall, which are extends three bays, gable roof with yellow glazed tile. There is a penthouse in the south of each side hall. On the south of the courtyard is the temple gate, extends three, depths two, yellow glazed tile and gable roof.

\section{NON-DESTRUCTIVE TESTING TECHNOLOGY}

As a new digital technology, non-destructive testing technology plays a big role for the ancient building conservation. Nondestructive testing is the adoption of physical mechanics or chemical properties to effectively test and inspect the relevant characteristics of the target object (such as shape, displacement, stress, optical properties, fluid properties, mechanics, etc.) without destroying the structure and operational performance of the detection target.With the research and development of new digital technology, non-destructive testing technology has integrated ground penetrating radar (GPR), stress wave and resistograph to overcome the shortcomings of single testing technique and increase the accuracy of the test results. Comprehensive comparison and data analysis would improve the accuracy of the location and condition of the damaged parts, and make it possible to explore a new way to repair damaged wood structure. Non-destructive testing technologies have overcome the shortcomings of the traditional detection method, and can be used to visually assess the condition, even internal, of timber and stone structure. Several common non-destructive testing technologies applied in the research of Ancestral Temple in Mukden Palace.

\subsection{D Scanning}

School of architecture of Tianjin University has organized students measuring the Dazheng Hall in 1964 and the Eight Banners' Pavilion and Ancestral Temple complex in 1991. However, due to limited conditions, only hand-painted paintings were available at that time. In 2016 and 2017, research group used $3 \mathrm{~d}$ scanning to measure the whole complex Ancestral Temple and Dazheng Hall in order to mark the wooden frame and stylobate more accurately and prepare data for the follow-up work. Based on both files above and regional measurement again, the $\mathrm{CAD}$ measuring pictures came out.

In the process of problem showing, figures of CAD provide convenience for marking problems and dimensional measurement. The point cloud pictures of 3D scanning (Figure. 4) provides accurate images and current situation.

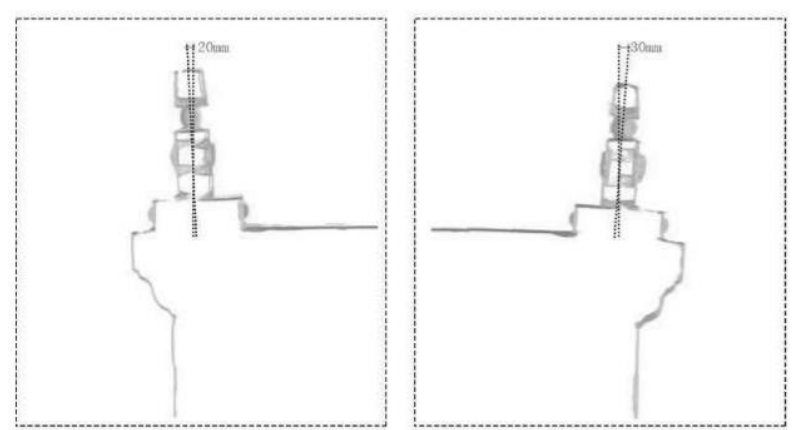

Figure. 4. Part of southwest and southeast stony frieze panel.

\subsection{Ground Penetrating Radar}

Ground penetrating radar (GPR) is a fast and efficient, highprecision non-destructive testing technology. In the beginning, radar detection technology was mainly used for underground exploration, while later, with the development of highfrequency electronic technology and computer data processing technology, GPR was also used in expanding fields.

As shown in the Figure. 5 and 6, the ground penetrating radar scanned below stylobate at the southeast corner of Dazheng Hall from north to south. Clear information shows that there are empty phenomena existing approximately at the 2.8 meters depth below $800 \mathrm{~mm}$ to $3000 \mathrm{~mm}, 6$ meters depth below 1000 $\mathrm{mm}$ to $3200 \mathrm{~mm}, 14.2$ meters depth below $400 \mathrm{~mm}$ to $1300 \mathrm{~mm}$.

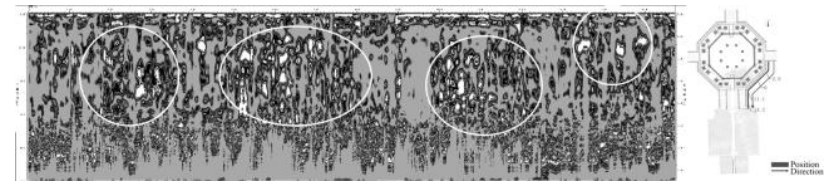

Figure. 5. Picture of southeast ground penetrating radar waveform.

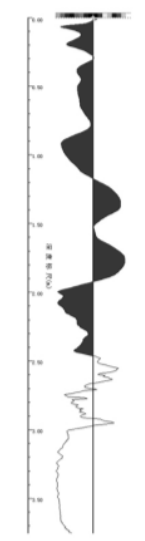

$2.8 \mathrm{~m}$ at the single-channe

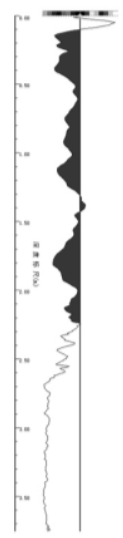

$6 \mathrm{~m}$ at the single-channe

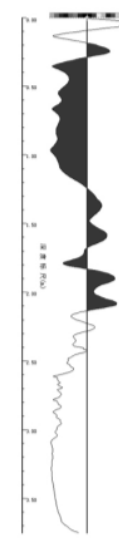

$11.1 \mathrm{~m}$ at the single-channe

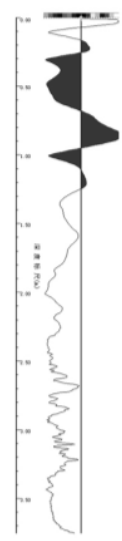

$14.2 \mathrm{~m}$ at the single-channe
Figure.6. GPR detection analysis of the southeast of stylobate.

In the restoration project of Ancestral Temple in Mukden Palace, ground penetrating radar (GPR) was mainly used to detect the relationship between wall settlement and foundation collapse, so as to probe into the mechanism of building settlement, which would be helpful to formulate the restoration plan. 


\subsection{Stress Wave}

Stress wave technology, detecting wave velocity and vibrational spectrum through sensors, is one of the most common methods of non-destructive testing of wood and wood-based composites. Depending on the actual diameter of the detected object, we can arrange $6,8,10$ or even more sensors around the detection section. The shorter the diameter is, the fewer sensors are needed. And the more sensors, the more accurate the test value will be. The height of the detection section was determined by the height, the appearance damage and the surrounding environment of the wood structure. Researches have shown that stress wave of healthy wood propagates in a certain range of velocity. If the wood decay or being worm-eaten, the propagation velocity would decrease sharply. Where wave speed is lower than the speed of healthy wood, the part can be judged as decayed or worm-eaten. According to the propagation speed of the internal structure of the wood, defects and damage can be encoded on pseudo color image, where unhealthy parts are indicated by red and blue, and healthy parts by green and yellow.

First, measure the circumference of the target structure. In the main hall, the circumference of D5 pillar at the height of $20 \mathrm{~cm}$ (Figure.7) was about $320 \mathrm{~mm}$. The perimeter was evenly divided into 10 parts by 10 sensors (FAKOPP) which could detect stress wave. Knock each sensor 3 times with a small hammer, and the average propagation time was taken as the propagation time of the measurement sensor point. By combining the distance and propagation time between the measured points, the stress wave propagation velocity could be calculated, which were later process pseudo color image. As the image shows, the pillar is partially serious cracked outside, but remain healthy in the inside.
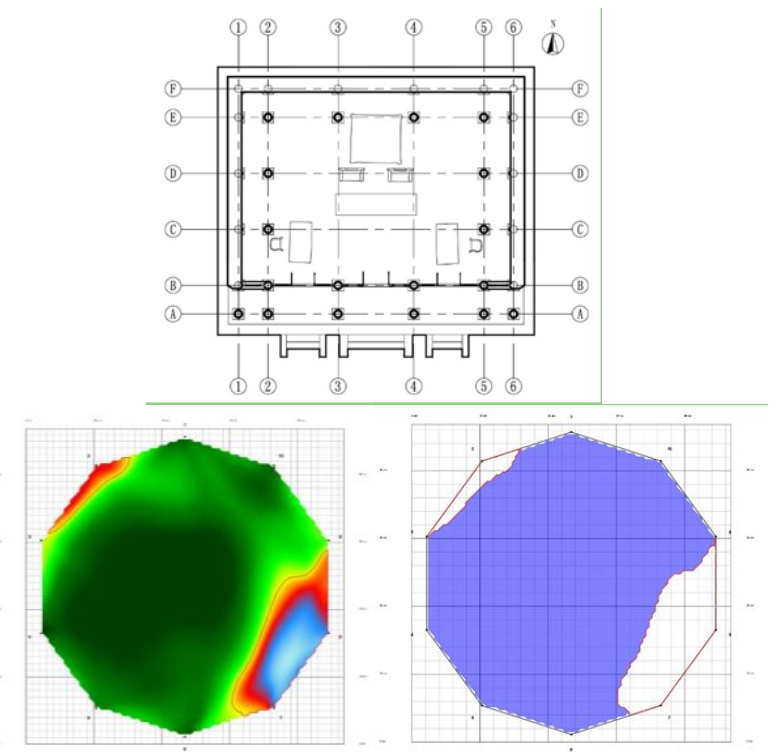

Figure.7 Stress wave pseudo image of D5 pillar of the main hall

\subsection{Resistograph}

The wood resistograph mainly composed of probe (and its protection device), the microcomputer system and the storage battery. To detect damages, the micro-probe, $1.5 \mathrm{~mm}$ in diameter, driven by motor, was stabbed into the interior of wood at a uniform rate. The computer recorded what the resistance pressure is for this process into the memory card, and print the output test photos, which were processed into two-dimensional graphics to indicate internal defects in the pillars section. The resistograph maps decayed degrees and wood age through different resistance values, and form curve image. Moreover, with the help of stress wave detection, which could find out the most damaged area for the probe to radially stab in, the damaged condition of wooden structure would be determined more accurately through the data comparison between the resistograph and stress wave.

\subsection{Concrete Ultrasonic Testing}

Due to limitation of the antenna of the ground penetrating radar, detection accuracy of the relatively small rectangular stone slabs is unsatisfactory, whereas ultrasonic test is more accurate and objective. In addition to emitting ultrasonic waves, principle is similar to that of ground penetrating radar which uses wave emission and reflection to create highly readable images. Figure. 8 shows concrete ultrasonic testing southeast rectangular stones from southwest to northeast and dark color in the dotted oval means bad condition of stone. It can be seen that the overall texture of southeast rectangular stone slabs of the hall is relatively poor, among which the internal damage of the first, second, third, fourth, sixth and eleven stones are more serious.

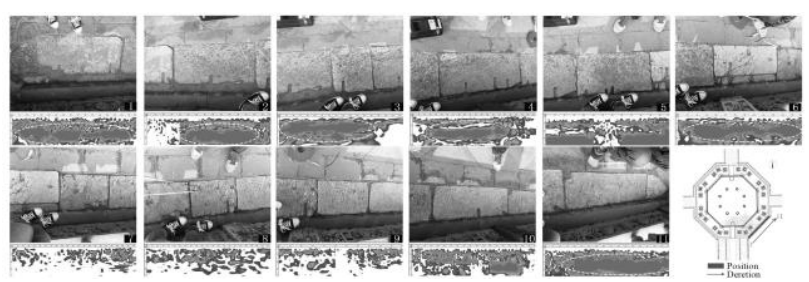

Figure. 8. Picture of southeast rectangular stones ultrasonic test.

\subsection{Mineral Element Analyzing}

Mineral element analysis instrument use "intelligent dynamic tracking" and "standard curve of nonlinear regression technique". Results can display direct reading percentage. On the one hand, difference data in the same component can be distinguished some replacement information in this survey. On the other hand, influence of water solubility can be discussed by pictures from the chemical point of view.

Obtained information is as follows: the content of calcium elements in stone materials such as upper and lower fillet and fascia (cyma), rectangular stone is higher, and the content of iron elements in stone materials such as frieze panel and capital stone is higher. (Figure.9)

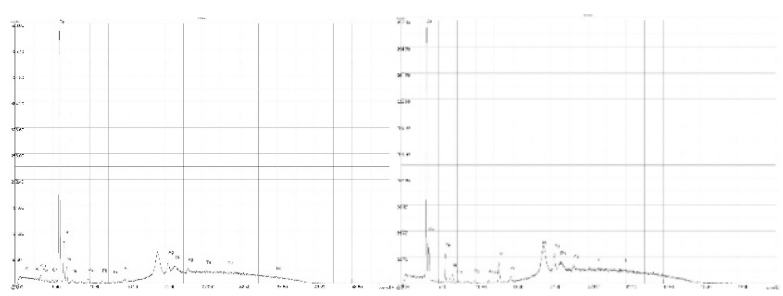

Figure. 9. A part of ore analyzing frieze panel pictures.

\section{TESTING RESULTS OF MUKDEN PALACE}

\subsection{Main Damages of Stone Stylobate of Dazheng Hall}

According to the analysis of the results of field investigation, in addition to the common problems of the damaged stone 
structure, there are many potholes on the surface of the rectangular stones of Dazheng hall. Due to historical reasons, its width is greater than upper eaves, which leads to direct erosion.

Based on figures from GPR detection and concrete ultrasonic test, fissure and structural joints containing certain moisture. As condensed water and rain to permeate stone inside, water content is raising. Because Shenyang Imperial Palace is located in the cold region, so freezing effect on the erosion of stylobate is obvious. When temperature drops in winter, water inside freezes and volume increases, causing pressure to stone. When the pressure exceeds capability of compressive strength of ordinary bricks and stones, further destruction will occur. The long frost period and the large daily average temperature difference in Shenyang area directly affect the water condensation and volatilization process in stones, resulting in the frequent alternation of dry and wet. Masonry has the property of moisture absorption to expand. So frequent expansion and contraction caused by dry and wet circulation result the surface of brick and stone loose and damaged, as well as lead to the mutual dislocation and deformation between blocks.

According to mineral element analyzing, the dissolution of water can separate the minerals contained in masonry into ions, especially of soluble minerals such as gypsum and rock salt. Water and carbon dioxide dissolved in water generate weak acid which improves liable to dissolve rock that mainly consist of calcium carbonate, causing material loss and decreasing rock breaking strength. At the same time, water dissolution changes the narrow channel of rock fracture into a wider channel, which also creates conditions for other destructive actions.

As for testing result, compared to other directions, southeast of stylobate has more problems including entirety slightly inclined, a certain amount of foundation holes, slanting frieze panel, bad situation of rectangular stones like concrete pavement. The main reason of damage should be the damage of masonry components and rammed earth materials caused by weathering erosion and freezing-thawing cycle. In general, the Dazheng hall stylobate is partially buried, with water apron missing. Platform outside part of the eaves column is obviously sinking, and frieze panel is partially tilted. The stony parts are partially fractured and damaged, and the surface is seriously air-slaked. Stone fracture mainly occurs in the imperial pass and steps, damaged about $40 \%$. The air-slake phenomenon mainly occurs in corner piers and rectangular stones, with damaged about $70 \%$. The frieze panel was recently replaced by about $30 \%$. Indoor and outdoor bricks are weathered and local fractured, about damaged $20 \%$. Intermediate pier of xumizuo is in bad condition by weathering with damaged about $70 \%$.

\subsection{Main Damages of Wooden Frame of Ancestral Temple}

\subsubsection{Cracks}

There are two kinds of cracks: entire crack and partial crack. The crevices of the temple were mainly in walls, beams, pillars, eave-rafters, etc.. For example, there were crevices in the east and west gable of the temple gate, which were about $20 \mathrm{~mm}$ wide at the top and $10 \mathrm{~mm}$ wide at the bottom. $80 \%$ pillars in the main hall had cracks, such as part of Liang Fang, boarded door, and eave-rafters. There are two main reason for the cracks. One is that the structures have been worn down by the years and fallen into disrepair. Long-time load has weakened the bearing capacity of beams and pillars and leads to cracking. The other reason is that the moisture erosion has caused different swelling or shrinkage inside and outside the wood fibers, which leaded to structure cracking.

\subsubsection{Decayed}

Years of humid environment and rain corrosion (result from unmaintained leaking roof) accelerated the deterioration of ancient wooden structures. The main hall, the temple gate, two side halls and two penthouses decayed in varying degrees. For example, the D2 pillar of the main hall, according to analysis and contrast of the data of the stress wave and the resistograph, was mild decayed in the inside and partly cracked in the outside.

\subsubsection{Settlement}

Uneven settlement of the foundation would cause the tilt and decline of the walls and wood structure. In Ancestral Temple in Mukden Palace, the most obvious settlement happened around the temple gate. Through the application of the ground penetrating radar, we found that the uneven settlement of the pedestal in the northwest corner of the temple gate leaded to the cracks in the wall and serious decline in the wood structure, threatening the stability and safety of the entire building.

\section{CONCLUSION}

Non-destructive testing (NDT) technology can be divided outside and inside testing. For outside, it still relies on traditional methods mainly including observing, measuring and photographing and adds new 3D scanning. These works testing are for overall construct in the earlier stage and provide convenience to after. As for inside, advanced technology contains ground penetrating radar exploring, concrete ultrasonic testing and mineral element analyzing acting on part under the stylobate, or inside the decayed pillars. All of these processes make up a relative all-sided testing.

There are still some problems existing. For earlier stage, information getting and analyzing are by body. If using infrared thermography may provide more accurately pictures. More advanced technology can be try if necessary.

Just for detection, this progress might be enough. If for problems forming, maybe the maximum impact causing empty inside stylobate is freeze thawing, but how about wind action for the structure? A further work can continue.

\section{ACKNOWLEDGEMENTS}

Acknowledgements of support for Natural Science Foundation of China (51508376).

\section{REFERENCES}

Chen Bochao and Piao Yushun, Buildings in Shengjing palace, China Architecture \& Building Press, 2007.

Zhang Yuanyi, Zhang Ying and Chen Xiaojuan, "Research on the key technology of $3 \mathrm{~d}$ laser scanning in measuring of ancient buildings", Architectural Journal, pp.29-33, Feb.2013.

Nuzzo L, Masini N, Rizzo E, Rosa Lasaponara, Integrated and multiscale NDT for the study of architectural heritage, 2008.

Li Zhuoqiu, Fang Xi and Shui Zhonghe, "Comparison of radar and ultrasonic imaging results in concrete detection", Juornal of 
Huazhong University of Science and Technology: Urban science edition,vol.4, pp.1-3, 2005.

Chen Shujun, Zhang Wei, Zhou Hongjun, Yu Haiming, Tian $\mathrm{Ge}$, et al. "Development of portable mineral element analyzer", Review and prospect of China's selection technology in ten years, ed: Wang Yunmin, pp.891-892, 2012.

Zhang Jinfeng, "Standard application of brick and stone structure in the repair of ancient buildings", Sciences of Conservation and Archaeology, vol.2, pp.79-86, 2010.

Duan Xinfang, Li Yudong, Wang Ping, non-destructive testing technology in the application of wood protection $[\mathrm{J}]$, timber industry, 2002.

Duan Xinfang, Huang Rongfeng, ancient building wood structure nondestructive testing and protection technology research [M], Beijing Construction Industry Press, 2008.

DAI Jian, CHANG Li-hong, QIAN Wei, LI Xin, Nondestructive testing method of ancient timber structure and repair and repair of damaged structures, Construction Technology, 2014.09.

Mei Bao, Deng Shikun, Hu Chaobin, application of ground penetrating radar technology in Yungang Grottoes maintenance, Journal of Engineering Geophysics, 2006.12.

Zhu Lei, Zhang Houjiang, etc., non-destructive testing of ancient architecture wood frame technology research at home and abroad, forestry machinery and woodworking equipment, 2011.03.

Huang Rongfeng, Wang Xiaohuan, etc., ancient building wood internal decay resistance test results quantitative analysis, Beijing Forestry University, 2007.11. 